\title{
Metabolic and haemodynamic effects of increased circulating adrenaline in man Effect of labetalol, an alpha and beta blocker
}

\author{
A D STRUTHERS, R WHITESMITH, J L REID \\ From the University Department of Materia Medica and the Department of Biochemistry, Stobhill General Hospital, \\ Glasgow
}

SUMMARY To simulate increased sympathoadrenal activity adrenaline was infused in normotensive subjects to achieve plasma adrenaline concentrations similar to those seen after myocardial infarction or hypoglycaemia. Adrenaline was infused after pretreatment for five days with labetalol $200 \mathrm{mg}$ twice daily or placebo given in a random order.

The rise in systolic blood pressure and the fall in diastolic blood pressure observed after the infusion of adrenaline $(0.06 \mu \mathrm{g} / \mathrm{kg} / \mathrm{min})$ were prevented by labetalol and no increase in blood pressure was seen. Adrenaline infusion after pretreatment with placebo caused a profound fall in the serum potassium concentration $(4 \cdot 12-3 \cdot 20 \mathrm{mmol}(\mathrm{mEq}) / \mathrm{l})$. Pretreatment with labetalol completely blocked adrenaline induced hypokalaemia (3.92-3.95 $\mathrm{mmol}(\mathrm{mEq}) / \mathrm{l})$. Adrenaline induced $\mathrm{T}$ wave flattening and QTc prolongation were also prevented by labetalol. Thus labetalol can prevent the electrocardiographic, haemodynamic, and hypokalaemic effects of increased circulating adrenaline in man. The combination of alpha and beta blockade appears to be required to block the haemodynamic effects of adrenaline, and labetalol may, therefore, be useful in controlling both the metabolic and circulatory responses during increased sympathoadrenal activity.

Intravenous beta blockade has been shown to have a beneficial effect when given early during the acute myocardial infarction..$^{-3}$ Early intravenous atenolol and propranolol have been shown to decrease infarct size and metoprolol to decrease mortality at one year after definite or suspected myocardial infarction. There are, however, little data on the metabolic and haemodynamic effects of different beta blockers during increased sympathoadrenal activity.

We have previously treated normotensive subjects with different beta blockers and infused adrenaline intravenously to produce similar concentrations of plasma adrenaline to those seen in patients during pathophysiological states such as myocardial infarction. ${ }^{4-6}$ Increased concentration of plasma adrenaline was associated with significant and substantial falls in serum potassium concentration, which could be of importance after myocardial infarction since hypokalaemia is a predisposing factor for ventricular

This study was presented in part at the British Pharmacology Society meeting at Sunderland, September, 1982.

Accepted for publication 26 May 1983 arrhythmias. ${ }^{78}$ In a previous study adrenaline induced hypokalaemia was completely prevented by non-selective beta blockade with timolol but only partially reduced by cardioselective beta blockade with atenolol. ${ }^{6}$ In addition to these metabolic differences between non-selective and selective beta blockers there were also haemodynamic differences. Adrenaline infused intravenously caused a small increase in systolic blood pressure and a decrease in diastolic blood pressure in untreated normotensive subjects. When they were pretreated with a nonselective beta blocker, however, adrenaline caused an increase in diastolic blood pressure which appeared to be due to peripheral alpha adrenoceptor stimulation

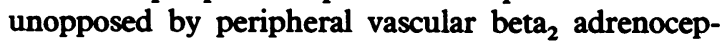
tors. This caused vasoconstriction and an increase in afterload, which in turn would be expected to increase myocardial oxygen requirements ${ }^{9}$ and may be undesirable after myocardial infarction.

We proposed that the combination of alpha and non-selective beta blockade should prevent the vasoconstrictor responses to adrenaline and also prevent hypokalaemia, as alpha blockade should prevent the 
alpha adrenoceptor mediated increase in vascular resistance. This hypothesis has been examined using pretreatment with labetalol, an agent with both alpha and beta blocking properties.

\section{Subjects and methods.}

Six normotensive subjects aged 23 to 31 years were studied. They had no symptoms or signs of cardiovascular disease and their resting electrocardiograms, chest $x$-ray films, full blood counts, and serum electrolyte concentrations were normal. The study was approved by the local research and ethical committee and each subject gave informed written consent. Each subject was studied on two occasions on the fifth day of treatment with either labetalol $200 \mathrm{mg}$ twice daily (Trandate, Allen and Hanburys Ltd) or placebo in a randomised single blind fashion.

On each study day intravenous cannulae were inserted into the antecubital veins of both arms. After a 30 minute rest period the subjects were given their morning dose of either labetalol or placebo and were then infused with $5 \%$ dextrose for one hour. They then received four 10 minute infusions of $0.01,0.02$, 0.04 , and $0.06 \mu \mathrm{g} / \mathrm{kg} / \mathrm{min}$ of 1-adrenaline (Antigen Ltd, Roscrae, Ireland) and blood pressure and heart rate were monitored frequently. Adrenaline $0.06 \mu \mathrm{g} /$ $\mathrm{kg} / \mathrm{min}$ was then infused for 90 minutes followed by $5 \%$ dextrose for a further two hours. Each infusion was delivered by a Braun Perfuser VI pump (Tewkesbury, UK) at $55 \mathrm{ml} /$ hour. Blood pressure, heart rate, serum electrolyte and plasma catecholamine concentrations were measured at frequent intervals for one and a half hours before, during, and for two hours after the adrenaline infusion.

Blood pressure was measured by a semiautomatic sphygmomanometer (Bosomat, Medical Electronics, Blackpool, UK) and heart rate from precordial electrocardiographic leads (Grass Model 7D, Grass Instrument Co, Quincy, Massachusetts, USA). The electrocardiogram was displayed continuously on an oscilloscope and was also recorded at intervals at $\mathbf{5 0}$ $\mathrm{mm} / \mathrm{s}$ as a permanent record. On these tracings the $T$ wave height was measured and the QT interval calculated from the onset of the $Q$ wave to the point where a tangent to the descending limb of the $T$ wave crossed the baseline. The QT interval was also corrected for heart rate (QTc) by the Bazett correction formula. ${ }^{10}$

The blood samples for estimation of serum electrolyte concentration were centrifuged within 30 minutes of collection and subsequently analysed on a Technicon SMA 6/60 (Technical Instrument Corporation, Tarrytown; New York, USA) using standard methods. The samples for estimating plasma adrenaline concentrations were collected into chilled heparinised tubes, centrifuged at $4^{\circ} \mathrm{C}$, and stored at $-70^{\circ} \mathrm{C}$ until assay. The sensitive radioenzymatic method of Da Prada and Zurcher ${ }^{11}$ was used to measure the plasma adrenaline concentrations. The overall profiles of systolic blood pressure, diastolic blood pressure, heart rate, and serum potassium concentration were analysed by repeated measures analysis of variance.

\section{HAEMODYNAMIC EFFECTS}

\section{Results}

Fig. 1 shows the haemodynamic effects of adrenaline between the end of the control dextrose infusion and the end of the $0.06 \mu \mathrm{g} / \mathrm{kg} / \mathrm{min}$ adrenaline infusion. On the placebo study day at the end of the control dextrose infusion the blood pressure was $106 \pm 12 / 68 \pm 11$ $\mathrm{mmHg}$ and the heart rate was $59 \pm 11$ beats/minute $($ mean $\pm S D, n=6)$. After the adrenaline infusion the systolic pressure rose and the diastolic pressure fell to $126 \pm 12 / 55 \pm 14 \mathrm{mmHg}(\mathrm{p}<0.005)$ while the heart rate rose to $70 \pm 9$ beats/minute $(p<0.01)$. On the labetalol study day the blood pressure was $111 \pm 11 / 65 \pm 5$ $\mathrm{mmHg}$ and the heart rate $60 \pm 7$ beats/minute at the end of the control dextrose infusion. After the adrenaline infusion on the labetalol study day the blood pressure and heart rate were unchanged at $108 \pm 14 / 66 \pm 10 \mathrm{mmHg}$ (not significant/not significant) and $58 \pm 8$ (not significant) beats/minute respectively. Adrenaline, therefore, caused a significant increase in systolic pressure and a decrease in diastolic pressure after placebo treatment. These haemodynamic changes were blocked by labetalol. Adrenaline produced no significant haemodynamic

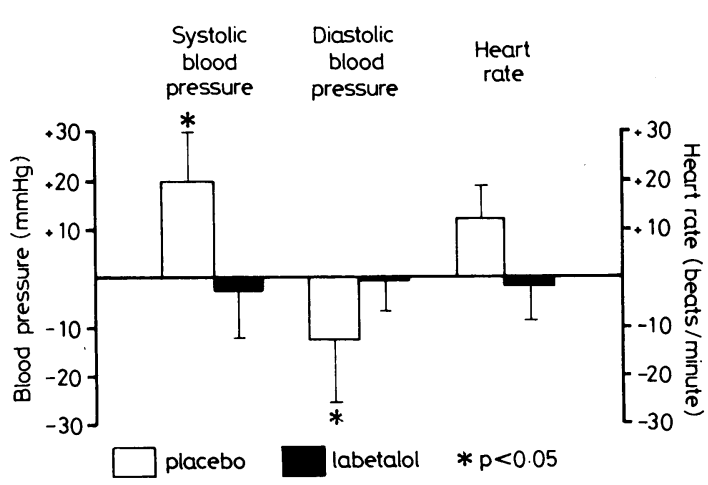

Fig. 1 Haemodynamic changes (mean $\pm S D$ ) between the end of the control dextrose infusion and the infusion of 0.06 $\mu \mathrm{g} / \mathrm{kg} / \mathrm{min}$ adrenaline after pretreatment for five days with either placebo or labetalol 200 mg twice daily. Statistical analysis by repeated measures analysis of variance. 
effects in the presence of labetalol: in particular no increase in diastolic pressure was seen as has been observed previously when adrenaline was infused in the presence of a non-selective beta blocker. ${ }^{612}$

\section{HYPOKALAEMIC EFFECTS}

Figs. 2 and 3 show the serum potassium concentrations after the infusion of adrenaline. At the end of the control infusion the concentration of serum potassium was not significantly different on the placebo or labetalol study days (placebo: 4.12 \pm 0.18 $\mathrm{mmol}(\mathrm{mEq}) / \mathrm{l}$; labetalol: $3.92 \pm 0.23 \mathrm{mmol}(\mathrm{mEq}) / 1$ $(m e a n \pm S D, n=6))$. At the end of the adrenaline infusion the mean (SD) serum potassium concentration had fallen significantly to $3.20 \pm 0.35 \mathrm{mmol}(\mathrm{mEq}) / 1$ $(p<0.05)$ after placebo pretreatment whereas there was no significant change in the serum potassium concentration when adrenaline was given after labetalol pretreatment $\quad(3.95 \pm 0.24 \quad \mathrm{mmol}(\mathrm{mEq}) / 1$ (not significant)). Labetalol, therefore, completely antagonised adrenaline induced hypokalaemia.

\section{ELECTROCARDIOGRAPHIC EFFECTS}

The electrocardiographic changes were examined at the end of the control infusion and at the end of the

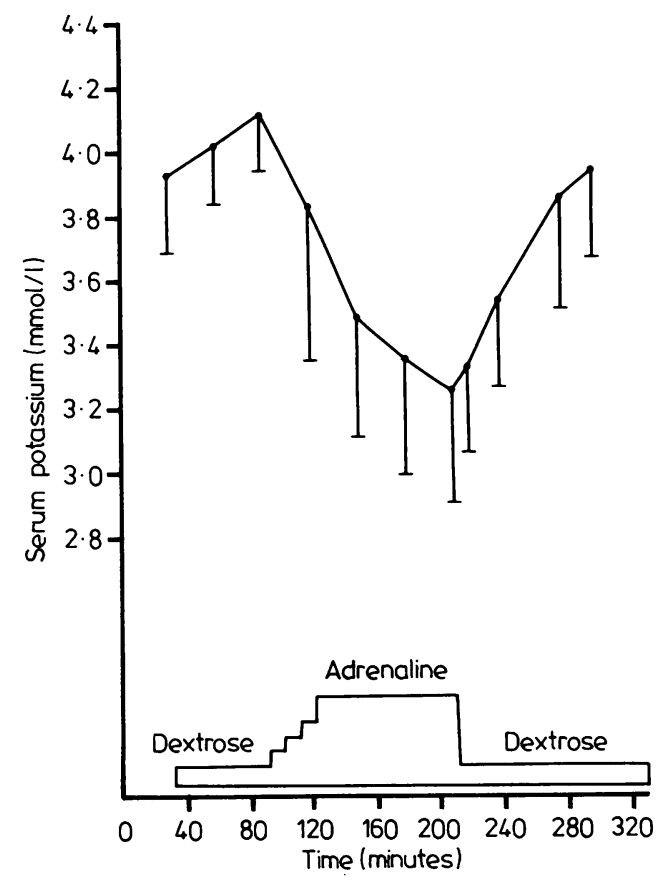

Fig. 2 Serum potassium concentrations (mean $\pm S D$ ) during infusion of $5 \%$ dextrose, $0.06 \mu \mathrm{g} / \mathrm{kg} / \mathrm{min}$ adrenaline, and $5 \%$ dextrose after pretreatment with placebo for five days Conversion: SI to traditional units-Potassium: 1 mmoll $=1 \mathrm{mEq} / \mathrm{l}$ adrenaline infusion and the results compared by paired t tests. Adrenaline caused pronounced flattening of the $T$ wave which was prevented by labetalol pretreatment ( $T$ wave height: placebo $-0.18 \pm 0.15$ $\mathrm{cm}, \mathrm{p}<0.05$ : labetalol: $+0.01 \pm 0.07 \mathrm{~cm}$ (not significant) (mean $\pm S D, n=6$ )). The QTc was prolonged by adrenaline from $0.36 \pm 0.01 \mathrm{~s}$ to $0.43 \pm 0.03 \mathrm{~s}$ $(\mathrm{p}<0.002)$. Pretreatment with labetalol prevented these adrenaline induced changes in QTc intervals $(0.36 \pm 0.01 \mathrm{~s}$ to $0.37 \pm 0.03 \mathrm{~s}$, not significant).

Table 1 shows the plasma adrenaline concentrations; these did not differ significantly between the placebo and the labetalol study day. In addition, the plasma adrenaline concentrations found during infusion of $0.06 \mu \mathrm{g} / \mathrm{kg} / \mathrm{min}$ adrenaline were similar to those observed in patients with acute myocardial infarction or patients with hypoglycaemia..$^{513}$

\section{Discussion}

Pretreatment with labetalol can prevent both the haemodynamic and hypokalaemic effects of increased circulating adrenaline. In particular, during increased sympathoadrenal activity no peripheral vasoconstriction is seen as occurs when the concentration of

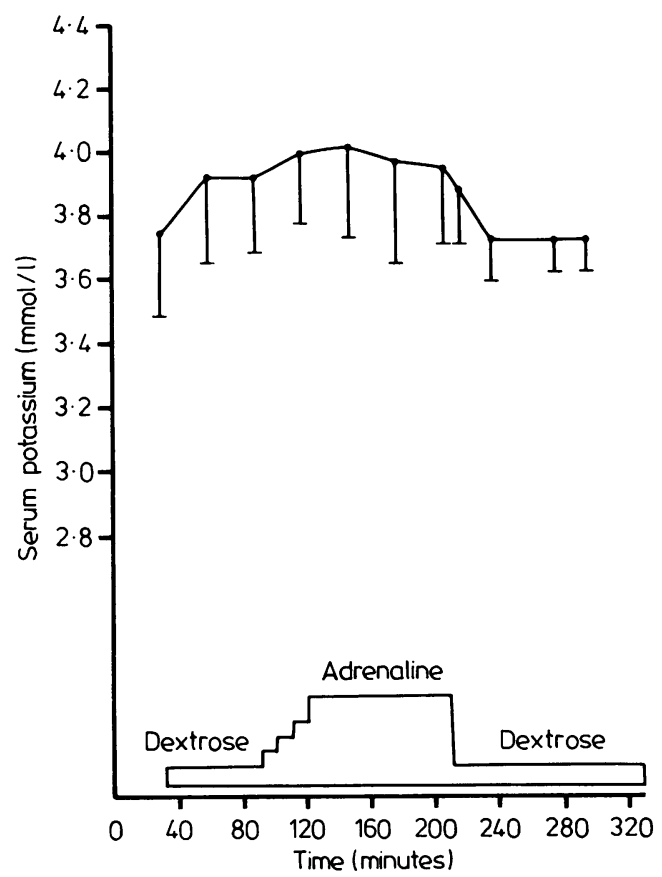

Fig. 3 Serum potassium concentrations (mean $+S D$ ) during infusion of $5 \%$ dextrose, $0.06 \mu \mathrm{g} / \mathrm{kg} / \mathrm{min}$ adrenaline, and $5 \%$ dextrose after pretreatmenit with labetalol $200 \mathrm{mg}$ twice daily for five days. Conversion: SI to traditional units-Potassium: 1 mmoll $=1 \mathrm{mEq} / \mathrm{l}$ 
Table Plasma adrenaline nmol/l concentrations (mean $\pm S D$ ) during the initial dextrose infusion, the $0.06 \mu \mathrm{g} / \mathrm{kg} / \mathrm{min}$ adrenaline infusion (60 min and 90 min), and the final dextrose infusion after pretreatment with either labetalol or placebo

\begin{tabular}{lll}
\hline Infusion & Placebo & Labetalol \\
\hline Dextrose & $0.23 \pm 0.23$ & $0.13 \pm 0.14$ \\
$\quad 0.06 \mu \mathrm{gg} / \mathrm{min}$ & & \\
Adrenaline $(60 \mathrm{~min})$ & $4.38 \pm 2.56$ & $4.57 \pm 1.09$ \\
$0.06 \mu g / \mathrm{kg} / \mathrm{min}$ & & \\
Adrenaline $(90 \mathrm{~min})$ & $3.16 \pm 1.75$ & $3.98 \pm 1.40$ \\
Dextrose & $0.13 \pm 0.07$ & $0.21 \pm 0.07$ \\
\hline
\end{tabular}

Difference in values between placebo and labetalol study day was not significant (repeated measures analysis of variance).

Conversion: SI to traditional units-Adrenaline: $1 \mathrm{nmol} \approx 0.183 \mu \mathrm{g}$.

plasma adrenaline is increased in the presence of non-selective beta blockade. ${ }^{12}$ Although these conclusions might be predicted from the pharmacological profiles of labetalol there are reasons why this might not have been the case in practice. Labetalol has greater beta blocking than alpha blocking activity. ${ }^{14} \mathrm{At}$ the dose used there might not have been sufficient alpha blocking activity to prevent the alphaadrenoceptor mediated vasoconstriction which was seen with non-selective beta blockade. In addition, the circulatory effects of infused adrenaline have been studied previously after labetalol treatment. Adrenaline caused a pronounced increase in diastolic blood pressure in the presence of labetalol. ${ }^{15}$ In that study, however, the adrenaline infusion rates were much higher than we have used and would lead to plasma adrenaline concentrations substantially in excess of those reported during increased sympathoadrenal activity in acute myocardial infarction, ${ }^{5}$ hypoglycaemia, ${ }^{13}$ or other severe stress in man.

Labetalol has been compared with propranolol in the treatment of patients with coronary artery disease. ${ }^{16}$ Pulmonary artery wedge pressure rose after intravenous infusion of propranolol but was unchanged after that of labetalol. The cardiac output fell after propranolol but was increased by labetalol. The additional alpha-adrenoceptor antagonism or vasodilator action of labetalol appears able to compensate for and overcome the left ventricular depression which is seen with beta blockade alone. Experience with intravenous labetalol in myocardial infarction is limited to those patients with both myocardial infarction and hypertension. ${ }^{17}$ In patients with increased pulmonary artery end diastolic pressures labetalol induced falls in pressure whereas in those with normal pressures they were unchanged. In addition to these haemodynamic improvements there is some evidence also that alpha-adrenoceptor mediated vasoconstriction may contribute to coronary artery spasm.1819 Whether the alpha-blocking action of labetalol is relevant in this regard remains to be established.

Adrenaline induced hypokalaemia in man has been reported previously ${ }^{12}$ and is confirmed in this study. At the cellular level adrenaline induced potassium influx appears to be mediated by a beta ${ }_{2}$ receptor linked to membrane bound adenosine triphosphatase. This has been demonstrated in skeletal muscle and in erythrocytes ${ }^{20}$ (HH Bodemann et al., 16th Annual Meeting of the European Society of Clinical Investigation, abstract No. 23) and may be a factor contributing to restoration of intracellular potassium and sodium concentration after depolarisation. In cardiac muscle, however, the effect of adrenaline is different, causing loss of intracellular potassium. ${ }^{21}$

The $T$ wave flattening which we found in this study may reflect myocardial intracellular hypokalaemia and be due to loss of potassium from both the intracellular and extracellular compartments in the myocardium, while potassium is correspondingly taken up by skeletal muscle tissue, red blood cells, and other unidentified tissues. The effect of adrenaline on potassium fluxes in vascular smooth muscle is not well established.

Thus increased concentration of plasma adrenaline causes pronounced hypokalaemia, $\mathrm{T}$ wave flattening, and QTc prolongation on the electrocardiogram. Both hypokalaemia and QTc prolongation can precipitate ventricular arrhythmias, ${ }^{622}$ and the arrhythmogenic effect of catecholamines may therefore be mediated both directly by effects on cardiac beta receptors and indirectly by hypokalaemia. Adrenaline induced QTc prolongation can be antagonised by atenolol, timolol, and in the present study also by labetalol. Adrenaline induced hypokalaemia is completely blocked by timolol and labetalol but not by atenolol. Of these three drugs, however, only labetalol is able completely to block the haemodynamic effects as well as the electrocardiographic and hypokalaemic effects of increased circulating adrenaline. These theoretical benefits of the combination of alpha and beta blockade remain to be tested in practice in acute myocardial infarction and in other clinical conditions in which increased sympathoadrenal activity is present.

\section{References}

1 Yusuf S, Ramsdale D, Peto R, et al. Early intravenous atenolol treatment in suspected acute myocardial infarction. Lancet 1980; ii: 273-6.

2 Peter T, Norris RM, Clarke ED, et al. Reduction of enzyme levels by propranolol after acute myocardial infarction. Circulation 1978; 57: 1091-5.

3 Hjalmarson $\AA$, Elmfeldt D, Herlitz J, et al. Effect on mortality of metoprolol in acute myocardial infarction. Lancet 1981; ii: 823-7.

4 Struthers AD, Reid JL, Whitesmith R, Rodger JC. Effect of intravenous adrenaline on the electrocardiogram, blood pressure and serum potassium. Br Heart $\mathcal{F}$ 1983; 49: 90-3. 
5 Cryer PE. Physiology and pathophysiology of the human sympathoadrenal neuroendocrine system. $N$ Engl F Med 1980; 303: 436-44.

6 Struthers AD, Reid JL, Whitesmith R, Rodger JC. The effect of cardioselective and nonselective beta blockade on the haemodynamic and hypokalaemic effects of increased circulating adrenomedullary hormones in man. Clin Sci 1983; 65: 143-7.

7 Thomas R, Hicks S. Myocardial infarction; ventricular arrhythmias associated with hypokalaemia. Clin Sci 1981; 60: 32P.

8 Donnelly T, Gray H, Simpson E, Rodger JC. Serum potassium in acute myocardial infarction [Abstract]. Scott Med F 1980; 25: 176.

9 Mason DT. Afterload reduction and cardiac performance. Physiologic basis of systemic vasodilators as a new approach in treatment of congestive heart failure. Am $\mathcal{Y}$ Med 1978; 65: 106-20.

10 Bazett HC. An analysis of the time-relations of electrocardiograms. Heart 1920; 7: 353-70.

11 Da Prada M, Zurcher G. Simultaneous radioenzymatic determination of plasma and tissue adrenaline, noradrenaline and dopamine within the femtomole range. Life Sci 1975; 19: 1151-74.

12 Massara F, Tripodina A, Rotunno M. Propranolol block of epinephrine induced hypokalaemia in man. Eur $\mathcal{F}$ Pharmacol 1970; 10: 404-7.

13 Rizza RA, Cryer PE, Gerich JE. Role of glucagon, catecholamines and growth hormone in human glucose counter-regulation. $f$ Clin Invest 1979; 64: 62-71.

14 Richards DA, Prichard BNC. Clinical pharmacology of labetalol. Br f Clin Pharmacol 1979; 8(suppl 2): 89S93S.
15 Richards DA, Prichard BNC, Hernández R. Circulatory effects of noradrenaline and adrenaline before and after labetalol. Br f Clin Pharmacol 1979; 7: 371-8.

16 Taylor SH, Silke B, Nelson GIC, Okoli RC, Ahuja RC. Haemodynamic advantages of combined alpha-blockade and beta-blockade over beta-blockade alone in patients with coronary heart disease. $\mathrm{Br} \mathrm{Med} \mathcal{F}$ 1982; 285: 325-7.

17 Timmis AD, Fowler MB, Jaggarao NSV, Vincent R, Chamberlain DA. Role of labetalol in acute myocardial infarction. Br $\mathcal{F}$ Clin Pharmacol 1982; 13: 111S-4S.

18 Levene DL, Freeman MR. Alpha adrenoceptormediated coronary artery spasm. fAMA 1976; 236: 1018-22.

19 Ricci DR, Orlick AE, Cipriano PR, Guthaner DF, Harrison DC. Altered adrenergic activity in coronary arterial spasm: insight into mechanism based on study of coronary hemodynamics and the electrocardiogram. Am $\mathcal{F}$ Cardiol 1979; 43: 1073-9.

20 Clausen T, Flatman JA. $\boldsymbol{\beta}_{2}$-adrenoceptors mediate the stimulating effect of adrenaline on active electrogenic $\mathrm{Na}-\mathrm{K}$ transport in rat soleus muscle. $\mathrm{Br} \mathcal{F}$ Pharmacol 1980; 68: 749-55.

21 Buckler KJ, Bhattacharya SS, Flear CTG. Actions of catecholamines and beta blockers on $\mathrm{Na}$ pump activity in heart and skeletal muscle. Clin Sci 1982; 63: 38P.

22 Doroghazi RM, Childers R. Time-related changes in the Q-T interval in acute myocardial infarction: possible relation to local hypocalcemia. Am $\mathcal{F}$ Cardiol 1978; 41:684-8.

Requests for reprints to Dr A D Struthers, Department of Clinical Pharmacology, Royal Postgraduate Medical School, Ducane Road, London W12 0HS. 